\title{
Implementasi Etnomatematika Berbasis Budaya Lokal dalam Pembelajaran Matematika pada Jenjang Sekolah Dasar
}

Rizki Wahyu Yunian Putra ${ }^{1}$, Popi Indriani ${ }^{2}$

1,2 UIN Raden Intan Lampung

Correspondence: $\square$ rizkiputra8916@yahoo.com

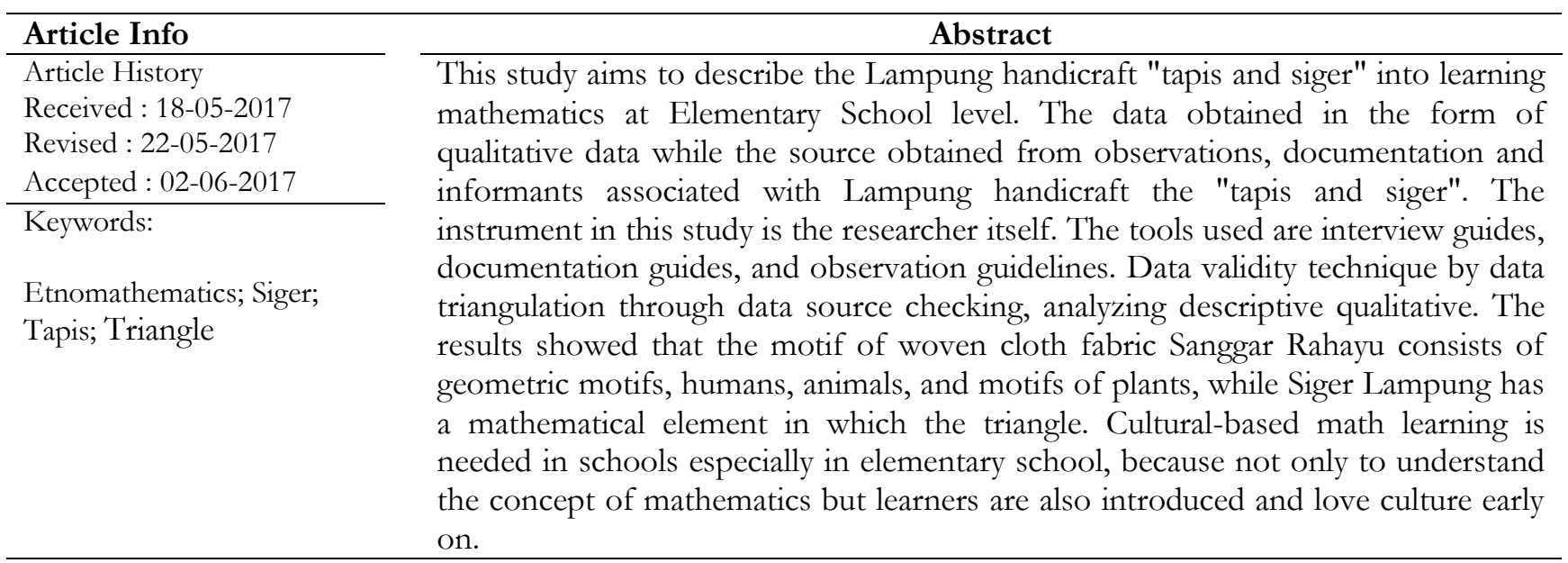

\section{PENDAHULUAN}

Kebudayaan dan pendidikan adalah dua unsur yang saling mendukung satu sama lain. Kebudayaan yang banyak aspeknya akan mendukung program dan pelaksanaan pendidikan [1]. Dengan demikian upaya memajukan kebudayaan berarti juga sebagai upaya memajukan pendidikan. Indonesia sudah dikenal memiliki budaya lokal yang begitu beragam. Dari Sabang sampai Marauke kebudayaan yang dimiliki tiap daerah pun tidak sama. Semestinya ini bisa menjadi modal Indonesia untuk menjadi amunisi ekspansi kebudayaan (pendidikan lokal). Namun yang terjadi adalah kebudayaan lokal Indonesia terus tergerus oleh globalisasi tanpa ada strategi pelestarian kebudayaan. Padahal peran pendidikan dalam melestarikan kelokalan Indonesia memiliki peran yang sangat penting. Selain sebagai pelestari, pendidikan juga dapat menjadi sebuah garda terdepan dalam kesuksesan sebuah Negara.

Salah satu bagian dari pendidikan yang diberikan di sekolah ialah pembelajaran matematika. Perkembangan ilmu pengetahuan dan teknologi tidak luput dari peran matematika di dalamnya. Matematika dibutuhkan untuk kebutuhan praktis dan memecahkan masalah dalam kehidupan sehari-hari. Misalnya, dapat berhitung, dapat menghitung isi dan berat, dapat mengumpulkan, mengolah, menyajikan dan menafsirkan data.

Pembelajaran matematika di SD merupakan salah satu kajian yang selalu menarik untuk dikemukakan karena adanya perbedaan karakteristik khususnya antara hakikat anak dengan hakikat matematika. Untuk itu diperlukan adanya jembatan yang dapat menetralisir perbedaan 
atau pertentangan tersebut [2]. Anak usia SD sedang mengalami perkembangan dalam tingkat berpikirnya. Ini karena tahap berpikir mereka masih belum formal, malahan para siswa SD di kelas-kelas rendah bukan tidak mungkin sebagian dari mereka berpikirnya masih berada pada tahapan (pra konkret) [3].

Manfaat lain yang menonjol adalah dengan matematika dapat membentuk pola pikir orang yang mempelajarinya menjadi pola pikir matematis yang sistematis, logis, kritis dengan penuh kecermatan. Matematika bagi siswa SD berguna untuk kepentingan hidup dalam lingkungannya, untuk mengembangkan pola pikirnya, dan untuk mempelajari ilmu-ilmu yang kemudian.

Proses pembelajaran matematika yang dilakukan saat ini cenderung terlalu kering, teoritis, kurang kontekstual dan bersifat semu. Pembelajaran pun kurang bervariasi, sehingga mempengaruhi minat siswa untuk mempelajari matematika lebih lanjut dan siswa sering menganggap pelajaran matematika sebagai pelajaran yang sulit dipahami. Pengajaran matematika di sekolah terlalu bersifat formal sehingga matematika yang ditemukan anak dalam kehidupan sehari-hari sangat berbeda dengan apa yang mereka temukan di sekolah. Oleh sebab itu pembelajaran matematika sangat perlu memberikan muatan/menjembatani antara matematika dalam dunia sehari-hari yang berbasis pada budaya lokal dengan matematika sekolah [4].

Etnomatematika merupakan salah satu aplikasi dari pendekatan kontekstual yang juga masih biasa juga digabungkan dengan pendekatan saintifik [5] [6]. Dalam proses pendidikan khususnya dalam kurikulum 2013 ini, meningkatkan nilai-nilai etika dan moral di kalangan remaja merupakan salah satu target yang ingin dicapai. Keberhasilan dalam membangun karakter siswa, secara otomatis membantu keberhasilan membangun karakter bangsa. Kemajuan suatu bangsa tergantung pada bagaimana karakter orang-orangnya, kemampuan intelegensinya, keunggulan berpikir warganya, sinergi para pemimpinnya, dan lain sebagainya. Dengan mengimplementasikan pendekatan etnomatematika diharapkan guru dan siswa mendapatkan ide tentang etnomatematika dan akhirnya dapat meningkatkan prestasi belajar matematika [7].

\section{METODE PENELITIAN}

Metode Penelitian yang digunakan adalah metode penelitian kualitatif deskriptif [8]. Teknik analisis data yang digunakan dalam penelitian ini sebagai berikut (a) Analisis Data Observasi, (b) Analisis Data Wawancara; (1) Reduksi Data, (2) Penyajian Data, (3) Penarikan Kesimpulan. Pemeriksaan keabsahan data, uji kredibilitas data diperiksa dengan teknik (perpanjangan pengamatan, peningkatan ketekunan pengamatan, triangulasi, pengecekan teman sejawat, pengecekan anggota, analisis kasus negatif,dan kecakupan referensial). Pada penelitian ini, teknik yang digunakan adalah triangulasi sumber.

\section{HASIL DAN PEMBAHASAN}

\section{Motif Tenun Kain Tapis yang Diproduksi oleh Sanggar Rahayu Galery Tanjung Seneng, Bandar Lampung}

Pada dasarnya, banyak motif yang telah diciptakan oleh Sanggar Rahayu. Ide penciptaan motif ini diambil dari berbagai unsur bentuk. Motif yang telah diciptakan oleh Sanggar Rahayu 
ini meliputi, motif tumbuhan, hewan, laut, dan penambahan teknik sulam usus. Penjelasan lebih lanjut dari Rahayu, bahwa Sanggar Rahayu Galery menerapkan 25 motif pada kain tenun tapis yang diproduksi. Dari beberapa motif tersebut terdapat motif yang menjadi motif andalannya. Adapun motif tersebut adalah motif mato kibaw, motif kapal tunggal, motif geometri, motif gajah dan manusia, motif bunga salur, dan motif modifikasi. Selanjutnya, adapun penjelasan dari keenam motif tersebut adalah sebagai berikut: Unsur bentuk yang terdapat di dalam motif tersebut meliputi, unsur bentuk bunga, belah ketupat, dan sedikit unsur bentuk rantai. Unsur-unsur bentuk ini akan menjadikan tenin kain tapis ini menjadi indah dah menarik. Ini sering dipakai untuk menghadiri upacara adat Lampung [9]. Penyusunan motif ini deletakkan saling sejajar, karena motif ini berbentuk persegi. Jika disilangkan akan kurang menarik dalam perpaduan motif yang lain. Dalam motif tenun kain tapis ini terdapat banyak unsur bentuk didalamnya, yakni kapal tunggal, hewan burung, awak kapal, nahkoda kapal, hewan gajah, dan sebagai hiasan dipinggi adalah pucuk rebung. Bentuk kapal ini berbentuk perahu lesung tanpa cadik/dayung. Bagian haluan dan burutan datar, tetapi ada juga yang memiliki tanjung/cucur menjualang, melengkung persegi kedalam. Motif Goemetri yang digunakan sebagai ragam hias adalah bentuk persegi, bunga berkelopak empat, bentuk silang dan bentuk bunga geometris. Penempatan ragam hias dilakukan secara berulang dengan arah horizontal pada bidang kain. Ragam hiasa ini juga digunakan dalam motif tapis kaco. Dalam tapis geometris ini juga terdapat kaca-kaca untuk memperindah ragam hias pada motif tapis geometris ini. Motif hewan gajah merupakan salah satu hewan tunggang yang melambangkan derajat seseorang yang tinggi. Tapis yang menggunakan ragam hias ini pada umumnya dipergunakan oleh gadis-gadis atau istri para pejabat. Motif bunga yang terdapat pada kain tapis biasanya diterapkan juga pada kain tapis cucuk andak dan inuh. Ragam hias yang dipakai biasanya ada jenis bunga dan salur. Ragam hias bunga membentuk persegi pada bidang dasar kain. Kain tapis motif modifikasi motifnya seperti motif flora, fauna, kapal, geometri, dan pucuk rebung. motif yang telah tercipta itu telah banyak di modifikasi dengan teknik renda dan sulam usus. Dari modifikasi tersebut dapat menjadikan karakter pada motif tapis di Sanggar Rahayu, Tanjung Seneng, Bandar Lampung. Motif yang telah diciptakan tidak mengandung nilai-nilai simbolik karena motif-motif yang diciptakan hanya hiasan semata.

2. Karakteristik Motif Tenun Kain Tapis yang Diproduksi di Sanggar Rahayu, Tanjung Seneng, Bandar Lampung.

a. Motif yang Terinspirasi dari Alam sekitar

Penerapan motif kapal pada kain tenun tapis kapal yaitu motif yang tak beraturan. Motif geometri, motif non geometri dan motif campuran. Motif yang tak beraturan yang tidak beraturan yang diterapkan yaitu motif bentuk kapal dan awak kapal. Motif campuran yang diterapkan yaitu motif gajah beserta pawangnya. Motif pucuk rebung merupakan motif yang diambil dari tumbuhan bambu, yakni bambu yang masih muda. Motif pucuk rebung mempunyai bentuk yang simpel. Motif ini diterapkan pada kain tenun tapis yaitu motif non geometri, yakni motif pucuk rebung yang merupakan motif tumbuhan yang telah di stilasi. Menurut Rahayu komposisi motif yang diterapkan pada produk kain tapis diambil dari motif tumbuhan yang dikobinasikan dengan motif belah ketupat akan terlihat lebih menarik. Penerapan pad motif bagian atas diberi motif pokok yakni pucuk rebung sejenis yang mempunyai ruas dan di 
susun saling sejajar. Motif pucuk rebung erat kaitannya dengan sistem (nilai) kemasyarakatan maupun sistem religi atau kepercayaan Tuhan Yang Maha Esa. Motif Pada Tenun Tapis Gajah Dan Manusia yang diterapkan pada kain tenun tapis gajah yaitu motif non geometri dan motif geometri. Unsur bentuknya meliputi motif Gajah, motif manusia (pawang), motif manusia menaiki perahu, serta motif rantai-rantai. Tapis Raja Medal menggambarkan tentang motif hiasan orang diatas rato ditarik oleh manusia, ayam nyecak konci, dan motif pucuk rebung. Pada motif tenun tapis Raja Medal ini terdapat ragam hias hewan tunggang, terkadang hewan tunggang yang digunakan adalah hewan gajah, kuda, dan kerbau. Karena hewan tersebut melambangkan seseorang yang memiliki derajat yang tinggi. Motif kaco pada tenun kain tapis ini dipadukan juga dengan motif geometri dan non geometri serta dilengkapi dengan kaca-kaca. Motif pelengkap juga yang digunakan adalah motif bunga salur yang telah distilasi dari bentuk tumbuhan yang menjulur kemudian dibuat menjadi bentuk bunga sehingga disebut bunga salur. Kain tapis agheng merupakan ragam hiasnya disulam dengan benang emas dan sutera yang membentuk motif burung, bunga, pucuk rebung, dan hewan naga. Serta terdapat tempelan kaca kecil-kecil berguna untuk memperindah motif tapis agheng ini. Warna dasarnya berwarna merah hati dan hitam yang terbuat dari benang kapas. Kain tapis agheng ini biasanya dipakai oleh para gadis-gadis Lampung Saibatin/Pesisir [10]. Motif bintang merupakan salah satu motif andalan yang diciptakan oleh Sanggar Rahayu. Komposisi motif ini biasanya dikombinasikan dengan motif pucuk rebung, bulan, dan dan kayu aro. Peletakan motif bulan bintang ini adalah diletakkan secara berurutan/sejajar dan di selang seling dengan motif bulan. Motif bulan bintang ini biasanya digunakan dalam tapis limar juga. Kayu Aro merupakan unsur bentuk yang terdapat pada motif tenun tapis tuho yang memiliki makna kesuburan dan memiliki keyakinan bagi masyarakat terdahulu. Kayu aro ini berbentuk batang dengan ranting yang bercabang kesegala arah. Motif ini melambangkan unsur nyawa yakni sebagai sumber kehidupan manusia, yang membangkitkan tenaga hidup manusia dan dapat disebut juga sebagai lambang keadilan dan kemakmuran masyarakat Lampung. Menurut Rahayu pada motif cucuk andak ini ada beberapa macam motif cucuk andak yakni, cucuk andak belambangan, cucuk andak Lampung Utara dan cucuk andak. Abung. Contoh motif yang saya ambil adalah motif tenun tapis motif cucuk andak belambnagan. Penerapan motif pada kain tapis adalah motif geometri dan non geometri. Sulam usus ini terbuat dari kain satin yang dijahit menyerupai usus ayam dan dirangkai sedemikian menarik untuk perpaduan antara sulam tapis dan sulam usus. Ada 2 sulam usus yakni Sulam Usus Bentuk Bunga Melati Sulam Usus Bentuk Bola. Sedangkan Sulam Renda terciptanya penggabungan ini karena pemilik Sanggar Rahayu terispirasi dari sulam renda untuk dalam sebuah seni kerajinan.

Setelah peneliti melakukan wawancara sekaligus observasi di Sanggar Rahayu Gallery dan pemangku adat Lampung. Peneliti selanjutnya melakukan observasi pada peserta didik untuk mengukur pemahaman tentang mata pelajaran matematika sekaligus mencintai budaya di daerahnya. Peneliti melakukan penelitian pada peserta didik kelas IV C di MIN 5 Bandar Lampung, dengan mengambil 5 orang siswa sebagai instrumen. Dari 6 soal tentang etnomatematika yang diberikan kepada peserta didik, penulis bisa menyimpulkan bahwa siswa lebih memahami pembelajaran jka ada objek/gambar yang dilihatnya, dan disini objek tapis dan siger sangat berhubungan dengan pembelajaran bangun datar kelas IV tersebut. 


\section{SIMPULAN DAN SARAN}

\section{Simpulan}

Lampung kaya akan kebudayaan, pendidikan diharapkan dapat mengambil peranannya dalam pelestarian warisan tak ternilai tersebut. Matematika yang selama ini dipandang sebagai bidang studi yang jauh dari aktivitas budaya melalui penelitian ini diharapkan menjadi pioner bagi lahirnya pembelajaran pada bidang studi lain yang juga berbasis budaya, demi terjaganya proses enkulturasi di Pulau Pisang. Karena etnomatematika adalah jembatan bagi lahirnya peradaban manusia modern yang berbasis budaya. Karakteristik motif tenun kain tapis Sanggar Rahayu dapat disimpulkan menjadi dua yakni, 1) Motif yang terinspirasi dari alam sekitar, seperti, manusia, tumbuhan, binatang, bulan, bintang. 2) Terdapat penerapan teknik sulam usus dan sulam renda sebagai pembentuk motif, seperti, bentuk bola dan bentuk bunga melati, sedang yang terdapat pada sanggar-sanggar lain tidak memakai teknik sulam usus dan sulam renda. Motif kain tenun tapis Sanggar Rahayu dapat disimpulkan menjadi empat uraian, yakni 1) Motif geometri, diantaranya motif bentuk persegi, motif bentuk silang, motif bentuk bunga geometri; 2) Motif manusia, diantaranya, motif pawang, dan motif awak kapal; 3) Motif binatang, diantaranya, motif binatang gajah, motif binatang naga, dan motif burung; 4) Motif tumbuh- tumbuhan, diantaranya, motif pucuk rebung, motif pohon hayat, motif bunga salur, dan motif bunga melati. Dilihat dari gambar siger saibatin berlekuk 7 dan berbentuk segitiga sama kaki sedangkan Siger papadun berlekuk 9 dan berbentuk segitiga sama sisi. Peserta didik lebih memahami konsep matematika bidang bangun datar sekaligus mencintai dan memahami hasil kebudayaan daerahnya.

Tenun kain tapis merupakan barang keperluan masyarakat Lampung untuk pakaian upacara adat, upacara perkawina, kelahiran, khitanan, dan lain sebagainya, yang kini juga diproduksi oleh Sanggar Rahayu Tanjung Senang, Bandar Lampung. Saat ini kain tenun tapis semakin berkembang dan telah banyak dinikmati oleh masyarakat luas, khususnya Lampung. Sama halnya dengan siger Lampung, tidak hanya mengetahui jumlah siger Saibatin/Pepadun saja tapi harus mengetahui makna yang terkandung didalamnya. Perlu adanya pelatihan pembuatan desain motif agar Sanggar Rahayu dapat menciptakan motif-motif yang lebih menarik dari sebelumnya. Sanggar Rahayu harus mengembangkan karakteristik yang lebih menarik lagi agar ciri khas tersebut menjadi lebih terlihat dibanding dengan tenun tapis yang diproduksi disangar-sangar lainnya. Dijadikan ide alternatif pembelajaran matematika di dalam dan di luar kelas. Dijadikan acuan pada materi matematika lain selain bangun datar.

\section{DAFTAR PUSTAKA}

[1] Tilaar, Pendidikan Kebudayaan dan Masyararakat Madani Indonesia. Bandung: Remaja Rosdakarya, 2012.

[2] S. S. Fatimah, 'Implementasi Etnomatematika Dalam Pembelajaran Matematika Pada Jenjang Pendidikan Sekolah Dasar', Lentera Pendidik., vol. 15, no. 1, pp. 41-54, Jun. 2012.

[3] R. A. Sani, Pembelajaran Saintifik Untuk Implementasi Kurikulum 2013. Jakarta: Bumi Aksara, 2014. 
[4] U. D'Ambrosio, 'Journal of Mathematics Education at Teachers College', Spring - Summer, vol. 4, 2013.

[5] Ubiratan d'Ambrosio, 'Ethnomathematics and Its Place in the History and Pedagogy of Mathematics', Learn. Math., vol. 5, no. 1, pp. 44-48.

[6] L. Shirley, Using Etnomatematics to Find Multicultural Mathematical Connection. Shirley, 2005.

[7] D. Rahmawati, 'Efektivitas Pembelajaran Matematika Dengan Strategi React Berbasis Etnomatematika Dalam Meningkatkan Kemampuan Komunikasi Matematis Dan Cinta Budaya Lokal Siswa Smp Kelas VII', UIN Sunan Kalijaga Yogyakarta Jurnal Program Pendidikan Matematika, 2015.

[8] Sugiyono, Metode Penelitian Kuantitatif, Kualitatif dan ReD. Bandung: Alfabeta, 2015.

[9] Fachruddin and S. Sirotus, Tapis Lampung. Bandar Lampung: Pemerintahan Propinsi Lampung Dinas Pemerintahan Propinsi Lampung, 2003.

[10] Sabaruddin, Mengenal Adat Istiadat Sastra dan Bahasa Lampung Pesisir Way Lima. Jakarta Barat: Kemuakhian Way Lima, 2010.

[11] Sabaruddin, Sai Bumi Ruwa Jurai LAMPUNG Pepadun dan Saibatin/Pesisir. Jakarta: Buletin Way Lima Manjau, 2012. 